\title{
O PROTAGONISMO JUVENIL NA CONSERVAÇÃO DA ÁREA DE PROTEÇÃO AMBIENTAL COSTA DOS CORAIS
}

Gildo Rafael de Almeida Santana ${ }^{1}$

José Ulisses dos Santos ${ }^{2}$

Resumo: Com o objetivo de favorecer o desenvolvimento dos jovens, nas dimensões social, política e ambiental, foi iniciado em julho de 2013 o Projeto Jovens Protagonistas da Costa dos Corais. A metodologia que norteia as atividades é dialógica: busca a interação teoria-práxis. É fundamentado na perspectiva da educação ambiental crítica, popular e emancipatória. O projeto realiza encontros quinzenais com a participação de 27 jovens e possibilitou entre 2013 e 2014, a participação destes em 2 encontros do Fórum Socioambiental da Costa dos Corais, nas Conferências Regional, Estadual e Nacional de Meio Ambiente, em 5 reuniões do Conselho da Área de Proteção Ambiental Costa dos Corais, na execução de dois projetos de extensão do Instituto Federal de Alagoas.

Palavras-chave: Protagonismo Juvenil; Participação Social; Educação Ambiental; Unidade de Conservação.

1 Instituto Federal de Alagoas/Universidade Aberta do Brasil. E-mail: gildoraphael@gmail.com 2 Instituto Chico Mendes de Conservação da Biodiversidade.

E-mail: jose-ulisses.santos@icmbio.gov.br 


\section{Introdução}

Nos últimos anos a Educação Ambiental (EA) vêm sendo amplamente discutida como um fator de suma importância na sociedade atual, haja vista, que os impactos no meio ambiente causados pela ação humana vêm sendo cada vez mais constantes.

A Área de Proteção Ambiental Costa dos Corais (APACC) é uma Unidade de Conservação Federal (UC), essencialmente costeiro-marinha, localizada entre Maceió (AL) e Tamandaré (PE). Uma das diretrizes desta UC é o desenvolvimento socioambiental da população local, por meio de programas de EA e de capacitação comunitária. No entanto, muitos dos jovens dessa região ainda não têm uma participação ativa nas atividades de educação e sensibilização ambiental.

A EA nasce como um processo educativo que conduz a um saber ambiental materializado nos valores éticos e nas regras políticas de convívio social e de mercado, que implica a questão distributiva entre benefícios e prejuízos da apropriação e do uso da natureza (SORRENTINO et al., 2005, p. 288), ou seja, se apresenta como um dos instrumentos que pretendem contribuir na formação de cidadãos críticos em relação à sua realidade. Neste contexto, a juventude, através da compreensão crítica da sua realidade e do mundo que a cerca, é capaz de construir seu processo cognitivo e intervir na melhoria da qualidade de vida de suas comunidades. Por isso, é preciso que o educador esteja atento ao contexto social e histórico, para que possa desenvolver um programa de EA onde os jovens não sejam apenas coadjuvantes, mas possam estar atuando como protagonistas da transformação socioambiental. Isto só será possível através de uma proposta de EA crítica e emancipatória (LOUREIRO et al., 2009).

Segundo Sorrentino (1998, p. 30), os grandes desafios para os educadores ambientais são, de um lado, o resgate e o desenvolvimento de valores e comportamentos (confiança, respeito mútuo, responsabilidade, compromisso, solidariedade e iniciativa) e de outro, o estímulo a uma visão global e crítica das questões ambientais e a promoção de um enfoque interdisciplinar que resgate e construa saberes. A reflexão sobre as práticas sociais, em um contexto marcado pela degradação permanente do meio ambiente e do seu ecossistema, envolve uma necessária articulação com a produção de sentidos sobre a EA (JACOBI, 2003, p. 190).

$\mathrm{Na}$ região central da APACC, entre Porto de Pedras-AL e São Miguel dos Milagres-AL, onde está localizada a Zona de Conservação do Peixe-Boi, a economia local vem crescendo devido à ampliação da cadeia do turismo, tendendo a incrementar problemas socioambientais, como poluição dos recursos hídricos e destinação inadequada de resíduos sólidos. Neste contexto, os jovens possuem grande potencial transformador, podendo desenvolver ideias e ações inovadoras de sustentabilidade. Assim, o Projeto Jovens Protagonistas (JP) da Costa dos Corais tem como objetivo favorecer o desenvolvimento dos jovens, nas dimensões social, política e ambiental.

Revbea, São Paulo, V. 11, № 1: 327-334, 2016. 


\section{O Projeto}

O Projeto JP da Costa dos Corais, foi iniciado em julho de 2013, com a participação de 25 jovens, com idades entre 15 e 25 anos, distribuídos nos municípios de Porto de Pedras-AL e São Miguel dos Milagres-AL. Atualmente o projeto conta com a participação de 27 jovens

As comunidades alvo não possuem opções de lazer, espaços de socialização e atividades culturais satisfatórias para os jovens. A proposta é promover encontros permanentes de formação e construção coletiva de saberes, com temáticas diversas que possibilitarão uma visão crítica da realidade socioeconômica e ambiental em que vivem, estimulando a busca de alternativas de superação dos problemas, mesclando apropriação de conteúdo, ludicidade e formação de grupo.

O projeto realiza encontros quinzenais que são realizados no Instituto Yandê: Educação, Cultura e Meio Ambiente e na Base do CMA/ICMBio em Porto de Pedras-AL. Esses encontros de grupo servem de suporte teórico para a execução das atividades práticas, pois são nesses que são realizadas as dinâmicas de grupo que incentivam a amorosidade, o respeito mútuo, a observação, a reflexão-ação-reflexão, assim como as inteligências múltiplas.

A elaboração do plano de ação do projeto foi participativa, e todos os jovens presentes no primeiro encontro (Figura 1) puderam apresentar suas opiniões que foram registradas e, na maioria dos casos, já entraram como atividade.

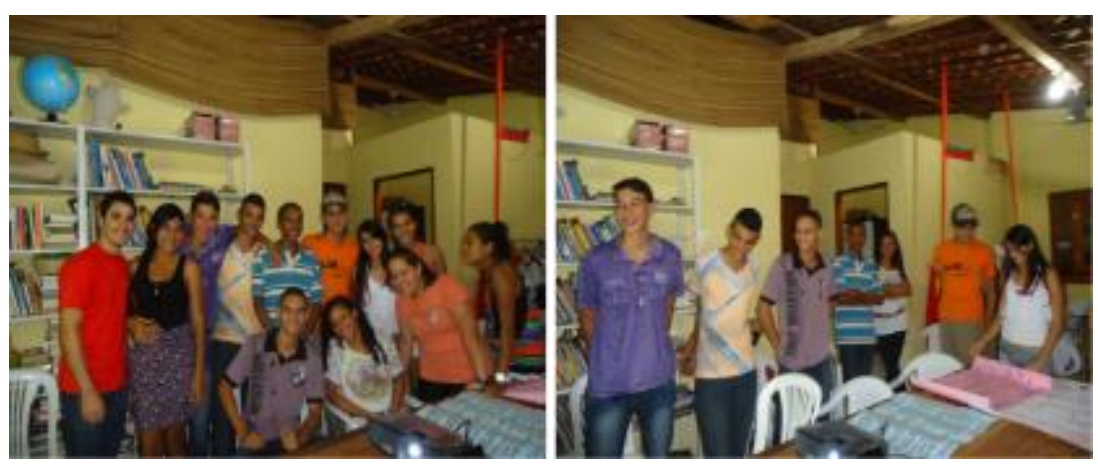

Figura 1: Primeiro encontro do Projeto Jovens Protagonistas da Costa dos Corais.

De acordo com Tozoni-Reis (2005, p. 271-272), a metodologia de pesquisa-ação em Educação Ambiental está centrada em três "práticas" que se articulam entre si: a produção de conhecimento, ação educativa e a participação dos envolvidos, tomando, como ponto de partida, um problema existente e detectado pelas equipes. Portanto, nesse projeto os JP deixam de ser objeto de estudos para serem pesquisadores e produtores de conhecimento de sua própria realidade. 


\section{Atividades desenvolvidas}

As ações do projeto foram iniciadas com a realização de diagnóstico participativo com a comunidade local, que teve como objetivo fazer um levantamento dos problemas ambientais. Para isso, os jovens foram a campo divididos em grupos, identificando e registrando os problemas. Após a identificação, os grupos compartilharam as informações entre si (Figura 2).

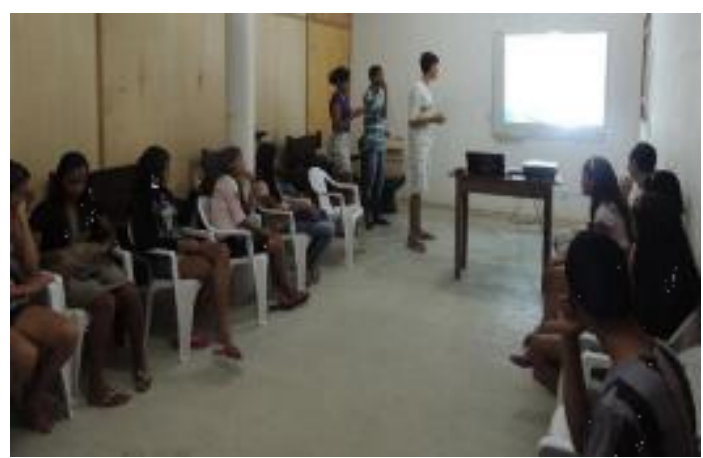

Figura 2: Apresentação dos resultados da pesquisa de campo.

Durante essa pesquisa de campo foram identificados nos dois municípios (São Miguel dos Milagres e Porto de Pedras) os seguintes problemas (Figura 3): lixão a céu aberto, falta de saneamento, poluição dos recursos hídricos, desmatamento de mata ciliar, poluição do manguezal, entre outros.
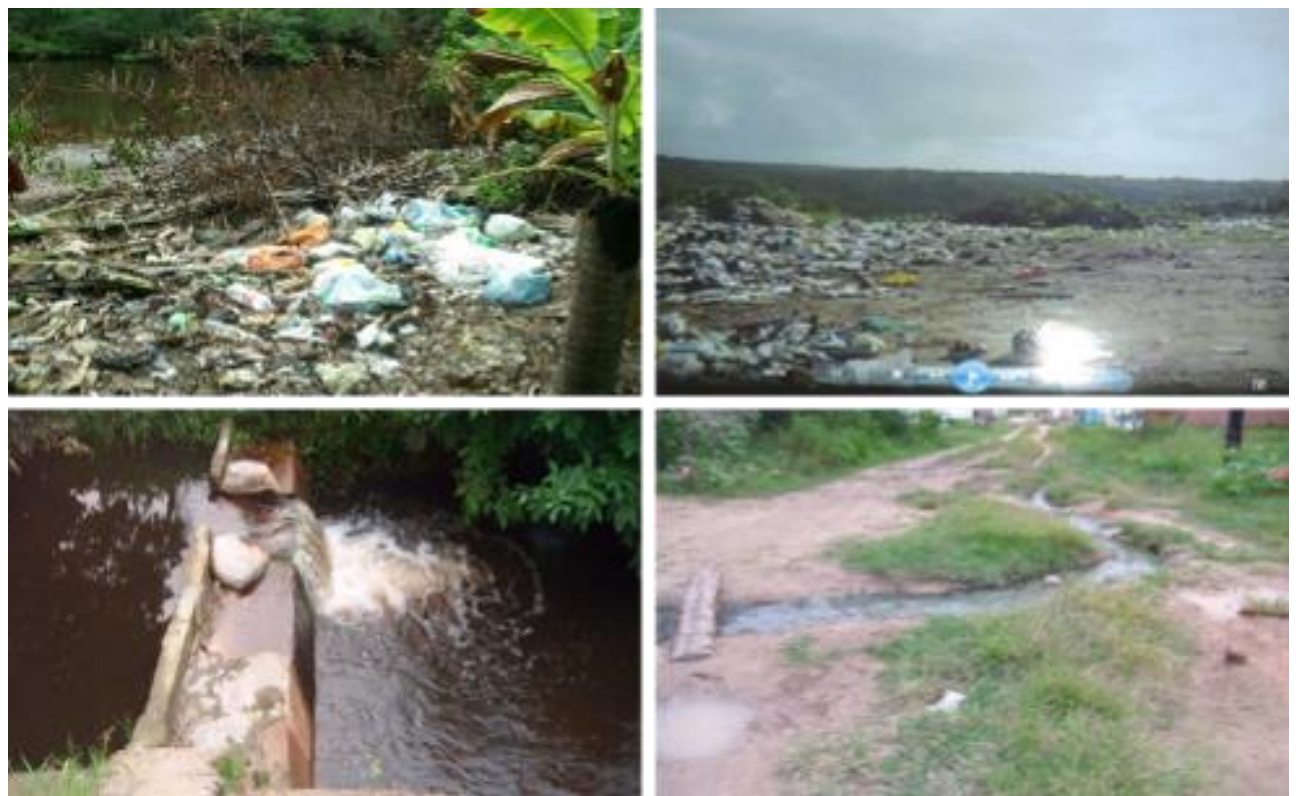

Figura 3: Problemas ambientais encontrados em São Miguel dos Milagres ( $A L$ ) e Porto de Pedras (AL). 
Através desse projeto os jovens têm participado de várias instâncias de discussões, como reuniões do Conselho da APACC e Conferências Regional, Estadual e Nacional de Meio Ambiente. Tiveram participação ativa em dois encontros do Fórum Socioambiental da Costa dos Corais, que foram realizados em agosto de 2013 e junho de 2014. A proposta desse Fórum é criar um espaço permanente de discussões entre os diversos atores da sociedade civil e do poder público sobre os problemas e conflitos socioambientais que envolvem a APACC.

No I Fórum (agosto de 2013), além dos jovens participarem dos grupos de discussões, também apresentaram um "Ecorap" (Rap ecológico) desenvolvido por um dos JP e, um Cordel da Costa dos Corais (Figura 4), que foi desenvolvido pelos JP durante uma oficina de literatura de cordel e nos encontros posteriores.

O povo pede respeito Quer saúde e educação Saneamento e moradia Para toda a população Chega de tanta miséria Desmatamento e poluição
A Área de Proteção Ambiental Costa dos Corais É uma Unidade de conservação

É permitido uso sustentável

Dos recursos com precaução

Para que a nossa reserva

Continue a sua evolução.

(Trecho do Cordel da Costa dos Corais)

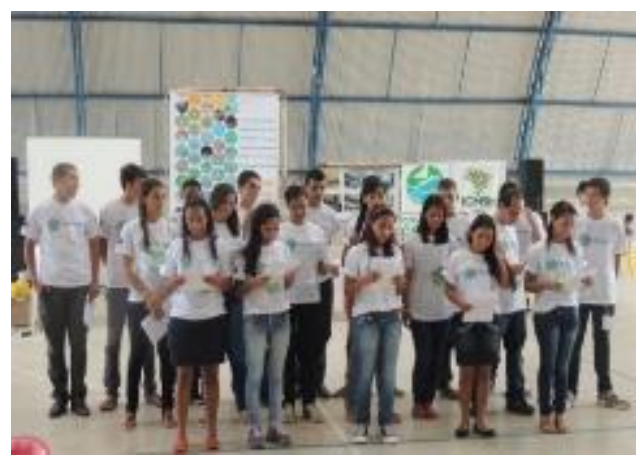

Figura 4: Apresentação do Cordel no I Fórum Socioambiental da Costa dos Corais.

Além da oficina de cordel, também foi realizada uma oficina de desenho, onde foram confeccionados desenhos ambientais que deram origem à todos os materiais de divulgação do Fórum, como cartazes e banners (Figura 5a), assim como a logomarca do Fórum (Figura 5b, página seguinte).

No II Fórum (junho de 2014), os JP já com representação na Comissão Executiva do Fórum, contribuíram com ideias, na logística e mobilização dos atores sociais envolvidos na proposta.

Assim como no Fórum, o projeto tem uma grande inserção dentro do Movimento Cidade Verde. Este movimento, surgiu da necessidade da realização e monitoramento de ações ambientais, sendo atualmente composto por inúmeras instituições como a Associação Milagrense de Turismo 
Sustentável (AMITUS), Instituto Yandê: Educação Cultura e Meio Ambiente, Associação de Turismo do Peixe-boi, CMA/ICMBio e pelos JP da Costa dos Corais, entre outros.

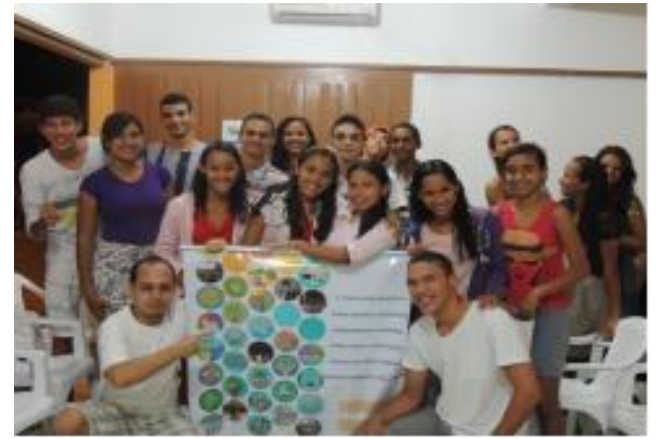

(a)

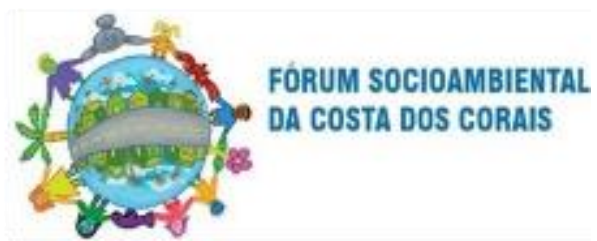

(b)

Figura 5: Resultados da oficina de desenhos: (a) Banner de divulgação do Fórum Socioambiental da Costa dos Corais e (b) Logomarca do Fórum.

Os JP têm participado ativamente dentro desse movimento, que é o maior movimento ambiental da Rota Ecológica. Entre as atividades realizadas, com a participação e apoio dos JP, estão os mutirões de limpeza de praia e manguezal (Figura 6), circuito tela verde (Figura 7a) com filmes ambientais em praças públicas e brincadeiras e jogos ambientais com crianças (Figura 7b).
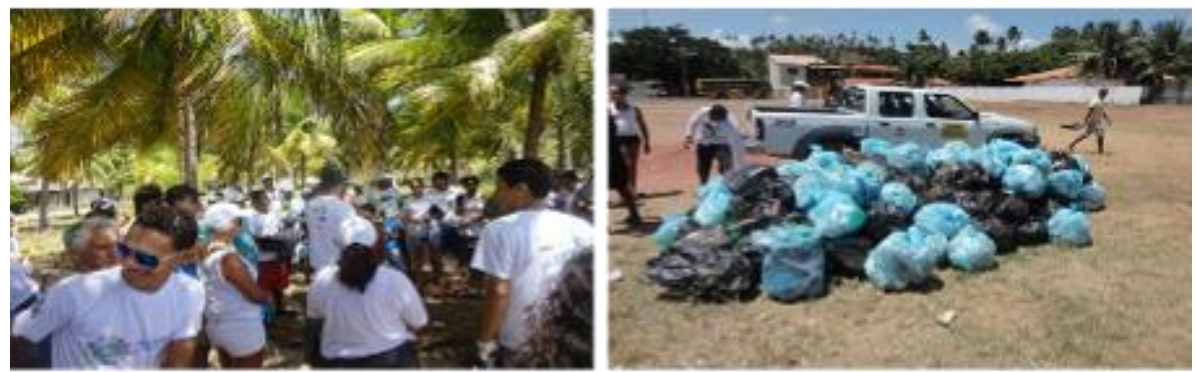

(a)
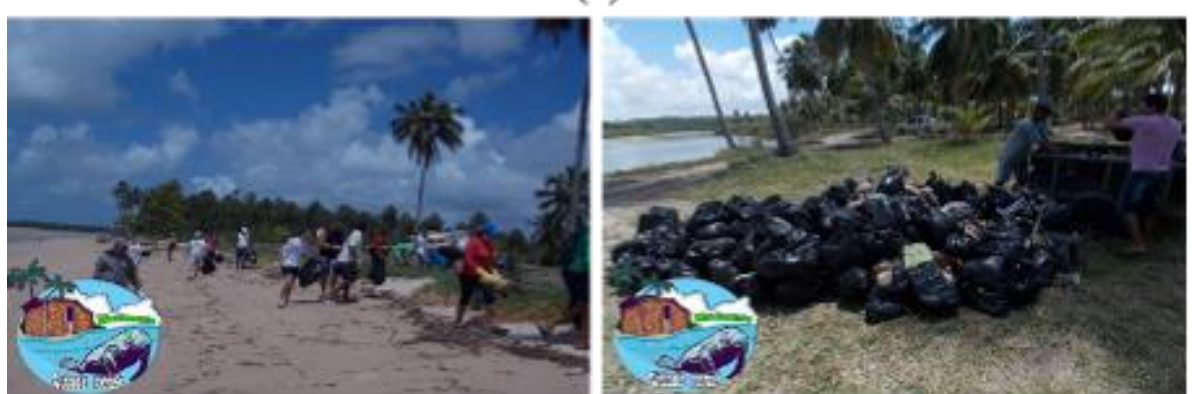

(b)

Figura 6: Mutirão de limpeza realizado pelo Movimento Cidade Verde: (a) Na Praia do Patacho até o centro de Porto de Pedras, em dezembro de 2013 e (b) Praia do Patacho-Porto de Pedras, em setembro de 2014. 


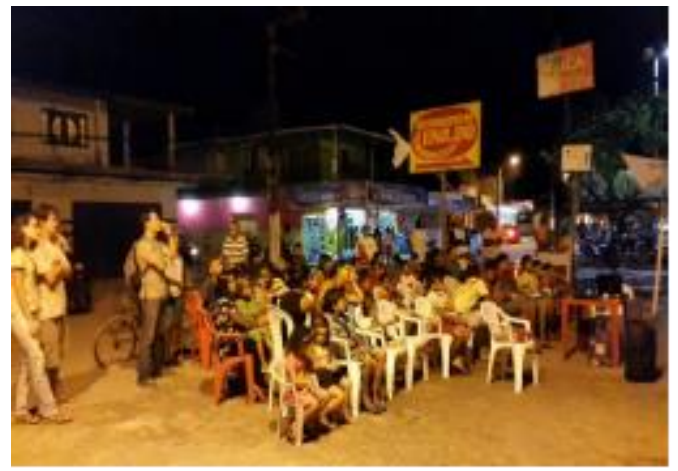

(a)

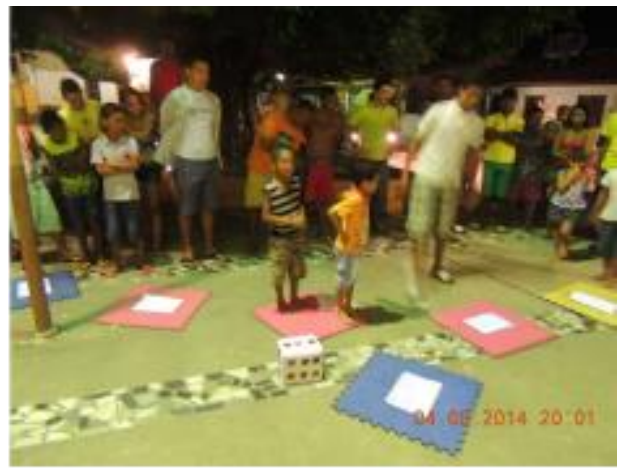

(b)

Figura 7: (a) Exibição de filmes ambientais no povoado Porto da Rua em São Miguel dos Milagres-AL e (b) Jogos ambientais com as crianças.

Ações de EA, são realizados com frequência e para que durante esses trabalhos houvesse a ludicidade e a espontaneidade dos participantes foi confeccionada pelos JP duas trilhas ambientais (Figura 8). Estas, tratam-se de um jogo com perguntas ambientais da região e normas adotadas para a conservação de espécies como o peixe-boi marinho, criticamente ameaçado de extinção, podendo ser aplicado com diferentes públicos e de diferentes faixas etárias, como crianças e adolescentes. As perguntas foram elaboradas pelos JP durante os encontros quinzenais, e monitoradas pela coordenação. Para a elaboração das perguntas os JP utilizaram como fonte de pesquisa a internet e livros.
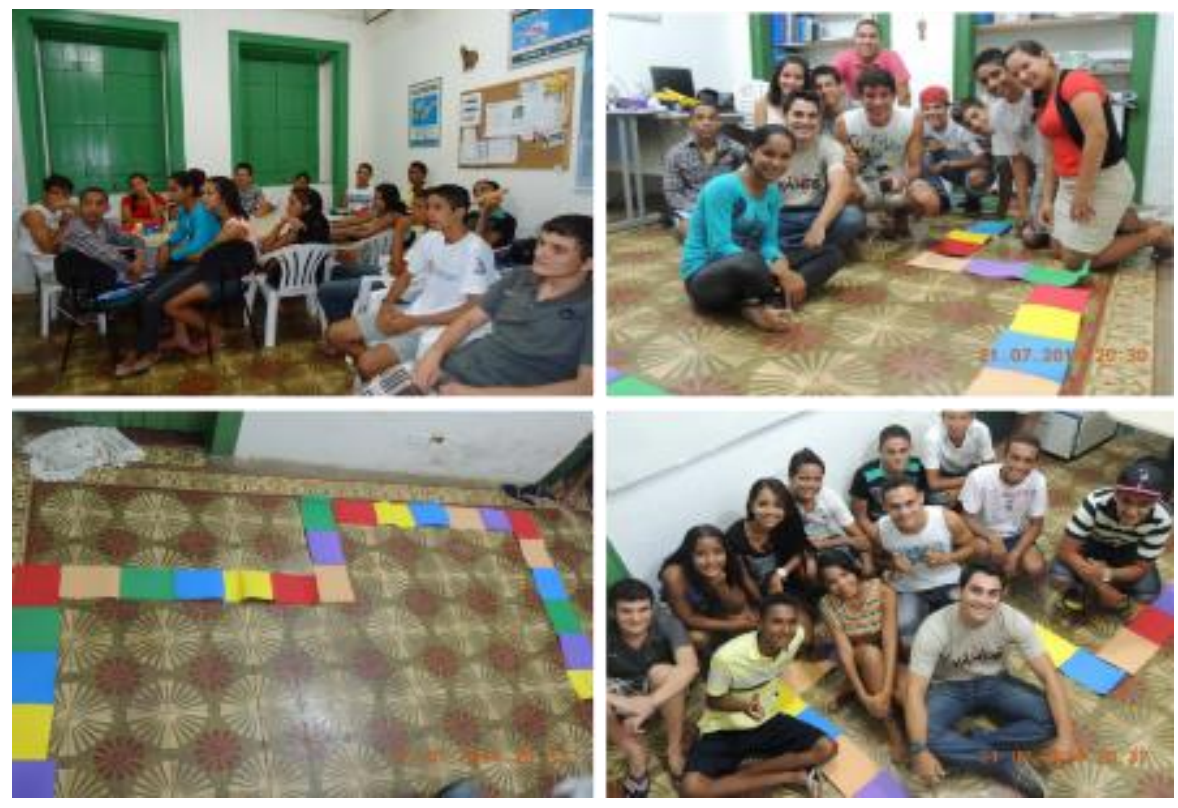

Figura 8: Encontro na base do CMA/ICMBio para elaboração do jogo trilha ambiental.

Após a confecção da trilha, o próximo passo é a realização de ações de EA em escolas públicas municipais e estaduais da região central da APACC. $O$ objetivo desse jogo é facilitar a aprendizagem dos alunos dentro do contexto 
ambiental, através da ludicidade e para isso o jogo é colorido e desmontável, podendo ser montado em diferentes formatos.

\section{Considerações finais}

A discussão sobre EA tem se intensificado em todo mundo e se confirmado como um assunto do cotidiano. Foi possível notar, durante o decorrer das ações do Projeto JP da Costa dos Corais, a aceitação por parte da comunidade e o desenvolvimento crítico desses jovens.

A pesquisa-ação usada para o desenvolvimento do projeto mostra a viabilidade da realização das ações de EA e a participação ativa da juventude abrindo a possibilidade para que obtenham um conhecimento aprofundado sobre sua realidade, da natureza, da degradação ambiental e de como eles, enquanto moradores, podem intervir nessa realidade.

Desse modo, a experiência desenvolvida dentro do Projeto JP da Costa dos Corais, comprova que a EA crítica e emancipatória utilizada no projeto tem mostrado verdadeiramente o papel da juventude dentro da APACC.

Os resultados desse projeto não podem ser medidos por completo, tendo em vista sua continuidade, mas diante dos resultados alcançados até o momento, é notório o quanto são positivos e que mudaram a percepção dos jovens no contexto socioambiental.

\section{Referências}

JACOBI, P. Educação ambiental, cidadania e sustentabilidade. Cadernos de Pesquisa [online]. n.118, pp. 189-206, 2003. ISSN 0100-1574. http://dx.doi.org/10.1590/S0100-15742003000100008.

LOUREIRO, C.F.B.; LAYRARGUES, P.P.; CASTRO, R.S. (Orgs.). Repensar a Educação Ambiental: um olhar crítico. São Paulo: Cortez, pp. 11-118, 2009.

SORRENTINO, M. De Tbilisi a Tessaloniki, a educação ambiental no Brasil. In: JACOBI, P. et al. (orgs.). Educação, meio ambiente e cidadania: reflexões e experiências. São Paulo: SMA. pp.27-32, 1998.

SORRENTINO, M.; TRAJBER, R.; MENDONÇA, P.; FERRARO JUNIOR, L.A. Educação ambiental como política pública. Educação e Pesquisa. São Paulo, v. 31, n. 2, pp. 285-299, 2005. http://dx.doi.org/10.1590/S151797022005000200010.

TOZONI-REIS, M.F.C. Pesquisa-ação: compartilhando saberes. Pesquisa e ação educativa ambiental. In: FERRARO JR., L.A. (Org.). Encontros e caminhos: formação de educadoras (es) ambientais e coletivos educadores. Brasília: Ministério do Meio Ambiente, pp. 267-176, 2005. Disponível em: $<$ http://mma.gov.br/port/sdi/ea/og/pog/arqs/encontros.pdf> Acesso em: outubro de 2014. 